\title{
Does climate policy promote development?
}

Michaelowa, Axel ; Michaelowa, Katharina

DOI: https://doi.org/10.1007/s10584-007-9266-z

Other titles: Climate or development

Posted at the Zurich Open Repository and Archive, University of Zurich ZORA URL: https://doi.org/10.5167/uzh-95272

Journal Article

Published Version

Originally published at:

Michaelowa, Axel; Michaelowa, Katharina (2007). Does climate policy promote development? Climatic Change, 84(1):1-4.

DOI: https://doi.org/10.1007/s10584-007-9266-z 


\title{
Does climate policy promote development?
}

\author{
Axel Michaelowa $\cdot$ Katharina Michaelowa
}

Received: 1 March 2007 / Accepted: 11 April 2007 / Published online: 11 May 2007

(C) Springer Science + Business Media B.V. 2007

\section{The increased relevance of climate policy}

With the publication of the IPCC's 4th Assessment Report (IPCC 2007) and the Stern Review on the economics of climate change (Stern 2006), the natural science background and the economic implications of climate change have become very clear. The IPCC states that "warming of the climate system is unequivocal" and the Stern Review stresses that "ignoring climate change will eventually damage economic growth" while "the benefits of strong, early action considerably outweigh the costs." These findings will put pressure on policymakers to embark on climate policy. This pressure will be reinforced by public reactions on an increasing number and intensity of extreme weather events. However, powerful interest groups representing the large greenhouse gas emitters will retard action to reduce greenhouse gas emissions and try to deflect policy attention to embark on adaptation to, rather than mitigation of climate change (for a public choice explanation of climate policy decision making with regards to emission reduction and adaptation see Michaelowa 2001). For politicians in industrialized countries, it is often easier to start policies that do not impact on powerful interest groups at home but can be implemented abroad and are financed through general taxpayers' or consumers' money. Thus, implementation of climate policy in developing countries is increasingly becoming attractive. Development assistance is flowing into renewable energy projects and afforestation, adaptation is becoming a buzzword in development agencies and the Clean Development Mechanism (CDM) which allows projects in developing countries to generate greenhouse gas reduction certificates becomes a hotbed of activity, with over 1,500 projects submitted within only 2 years, and that aim to generate more than 1.5 billion certificates.

\footnotetext{
A. Michaelowa $\cdot$ K. Michaelowa $(\square)$

Institute of Political Science, University of Zurich, Mühlegasse 21, 8001 Zurich, Switzerland e-mail: katja.michaelowa@pw.uzh.ch
}

\footnotetext{
A. Michaelowa

e-mail: axel.michaelowa@pw.uzh.ch
} 


\section{How could climate policy generate development?}

Often, it is uncritically assumed that there is an automatic synergy of climate and development policies, particularly in the case of greenhous gas emission reduction. The belief is that money spent on renewable energy and energy efficiency projects leads to a higher availability of energy, technology transfer and local job creation. This line of thought is reflected in the double target of the CDM which says that projects should at the same time assist developing countries in achieving sustainable development and assist industrialized countries to reach their emission targets.

In the context of adaptation to climate change, it is also generally thought that successful adaptation would entail development progress (e.g. Huq et al. 2006). Another variant of the belief in a positive correlation between adaptation and development is that adaptation is only possible if a society has reached a certain degree of economic maturity. Neither of the two is as straightforward as one may think (see also Adger et al. 2006).

This Special Issue of "Climatic Change" sets out to analyze whether emissions mitigation or adaptation to climate change really show synergies with development targets and whether mitigation policy (e.g. as embodied in the CDM) has provided development benefits. The idea was born out of a conference "Climate or Development?" organized at the Hamburg Institute of International Economics (HWWI) on October 28-29, 2005. The Special Issue consists of an introductory paper, one section on adaptation, and one section on the CDM.

In the introductory article, Michaelowa and Michaelowa (2007) discuss the role of official development assistance (ODA) in climate policy. During the last 15 years, an increasing amount of ODA has flown into projects reducing greenhouse gas emissions. For the different interest groups influencing climate and development policies, it is attractive to spend ODA for emission reduction through renewable energy and energy efficiency. However, only limited benefits with regards to the Millennium Development Goals, the major internationally agreed development objectives, accrue from such projects. As only at a medium-income level of development, greenhouse gas emissions start to increase rapidly, the countries which are the best targets for large-scale emission reductions do not correspond to those that should have a priority in receiving ODA.

The section on adaptation to climate change and development policy starts with an article on mainstreaming of adaptation in the practice of development agencies. Klein et al. (2007) assess efforts of six development agencies and international organizations (World Bank, OECD, DFID, GTZ, Norad and Swiss Agency for Development and Corporation) to screen their (or their members') project portfolio with regard to their projects' vulnerability to climate impacts. Analyzing these approaches, Klein and his co-authors start from the hypothesis that technological adaptation needs to be supplemented by non-technical measures to set up structures that make sure that the technologies are accessible and take local conditions into account. They emphasize the relevance of the institutional embedding of the adaptation activities in the development agency and the clear definition of assessment criteria. The second article by Yang et al. (2007) studies the reactions of farmers on a temperature increase of over $1{ }^{\circ} \mathrm{C}$ in the last three decades in Northeast China. This adaptation study is unusual as it assesses a situation where adaptation leads to net benefits compared to the situation before adaptation started. The boundary of growing frostsusceptible crops such as winter wheat has been shifted northwards and the rice growing area has been multiplied by a factor of five. Wheat yields have multiplied by a factor of 2.5 within 20 years. The authors stress the role of agricultural technology dissemination networks as well as state farms in spreading the news about temperature increase and crops 
now suitable for the region. As this adaptation has already taken place, it provides important insights for future adaptation processes.

The second section of this Special Issue, composed of four articles, focuses on whether the CDM has been able to promote development. Holm Olsen (2007) provides a literature review and carries out a meta-analysis of 19 studies on the CDM. She differentiates between forward-looking studies, studies addressing criteria and indicators for project evaluation, and studies of forestry projects. She concludes that there is a trade-off between the CDM target of supplying cheap emission credits and the promotion of sustainable development, and that the former target has taken precedence. In the following article, Sutter and Parreño (2007) evaluate 16 registered CDM projects using an innovative methodology for the assessment of the CDM's contribution to sustainable development. Their method defines three distinct indicators for sustainability and represents the first attempt of a quantitative sustainability assessment of CDM projects. The authors conclude that none of the analyzed projects score high on sustainability and "likelihood of real emissions reduction" simultaneously. They find that the large projects in their sample are having a low sustainability score and that over $95 \%$ of reductions come from projects with a low score.

The following two articles look at host countries that have been frontrunners in the implementation of CDM projects. Sirohi (2007) analyzes whether CDM projects in India contribute to poverty alleviation in rural areas. She first defines the characteristics of rural poverty and then looks at the poverty alleviation potential of each common CDM project type. Landless laborers do not benefit from the CDM induced price increases in agricultural residues and employment benefits for unskilled people are extremely limited. Only higher rural social strata can be expected to receive income from CDM projects, with the possible exception of sugarcane growers. Moreover, in India CDM projects are generally concentrated in areas with above-average incomes.

By looking at the energy supply structure of Amazonia, Borges da Cunha et al. (2007) analyze whether remote regions in Brazil benefit from the CDM. While having a substantial potential for renewable energy, the isolated mini-grids of Amazonia are generally supplied by diesel generators, using fuel subsidized by about $70 \%$ through a system of crosssubsidies. These subsidies represent a barrier to the use of renewable energy, a problem which has not been overcome despite numerous government programs to enhance access to rural electricity. Moreover, only 3\% of Brazilian CDM projects are located in Amazonia. Given the small size of potential projects in the region, Borges da Cunha et al. explain this lack of CDM activities with the relatively high investment costs and low reductions per project. In this context they emphasize the advantages of the recently agreed "programmatic CDM" which will allow bundling and will considerably reduce transaction costs for the coordination of many small projects.

\section{Climate policy is no magic bullet to achieve development}

In contrast to the belief of many, if not most policymakers, synergy between climate and development policy is limited at best. This is particularly important in the case of the CDM. The CDM has had a huge success in terms of mobilizing low-cost emission reductions but has not yet produced a substantial benefit for poverty alleviation and only limited support of sustainable social and economic development in the host countries. While the developing countries themselves have the opportunity to channel CDM investment into this direction, for example by introducing and applying stringent criteria for approval of CDM projects, 
these opportunities have so far not been seized. Similarly, non-governmental organizations (NGOs) have been rather inactive in this field. In principle, they could put a spotlight on the failure of the CDM with respect to development objectives, for example by utilizing the opportunity to submit public comments on CDM projects on the website of the UNFCCC Secretariat and by scrutinizing CDM projects publicly. However, after shutting down the web-based campaign "CDM Watch" in April 2005, NGOs have been strikingly silent in the CDM process (for an exception, see Lohmann 2006).

As adaptation funding is about to start only now, the evidence of the development impact of activities in this area is so far rather limited. It has to be avoided that adaptation funds vanish like a drop in the desert due to unclear criteria for the setup of the corresponding projects. As in the case of the CDM, there has to be an active guidance to avoid that adaptation funds are flowing into the coffers of the least vulnerable and thus exacerbate existing inequalities. This requires the development of a set of criteria for project selection. Moreover, the lessons learnt from four decades of development cooperation should be taken into account if the intention to contribute to sustainable social and economic development is to be taken seriously.

Acknowledgements We thank the Hamburg Institute of International Economics where we organized the conference "Climate or Development?" in October 2005. Funding for this conference which provided room for the initial discussion of the ideas presented in this Special Issue, was also provided by the Hamburg Institute.

\section{References}

Adger N, Paavola J, Huq S, Mace MJ (eds.) (2006). Fairness in adaptation to climate change, MIT Press, Cambridge

Borges da Cunha K, Walter A, Rei F (2007) CDM implementation in Brazil's rural and isolated regions: the Amazonian case. Clim Change 84(1-2)

Holm Olsen K (2007) The clean development mechanism's contribution to sustainable development: a review of the literature. Clim Change 84(1-2)

Huq S, Reid H, Murray L (2006) Climate change and development links, Gatekeeper series no. 123, IIED, London

IPCC (2007) Climate change 2007, 3 vols. Cambridge University Press, Cambridge

Klein R, Eriksen S, Næss L, Hammill A, Tanner T, Robledo C, O’Brien K (2007) Portfolio screening to support the mainstreaming of adaptation to climate change into development assistance. Clim Change 84(1-2)

Lohmann L (2006) Carbon trading - a critical conversation on climate change, privatisation and power. Development dialogue no. 48, Dag Hammerskjöld Foundation, Uppsala

Michaelowa A (2001) Mitigation versus adaptation: the political economy of competition between climate policy strategies and the consequences for developing countries. HWWA discussion paper no. 153, Hamburg

Michaelowa A, Michaelowa K (2007) Climate or development: is ODA diverted from its original purpose? Clim Change 84(1-2)

Sirohi S (2007) CDM: is it a "win-win" strategy for rural poverty alleviation in India? Clim Change 84(1-2)

Stern N (2006) Stern review: the economics of climate change, London

Sutter C, Parreño C (2007) Does the current Clean Development Mechanism (CDM) deliver its sustainable development claim? An analysis of officially registered CDM projects. Clim Change 84(1-2)

Yang X, Lin E, Ma S, Ju H, Guo L, Xiong W, Li Y, Xu Y (2007) Adaptation of agriculture to warming in northeast China. Clim Change 84(1-2) 